\title{
Water Vapor Effects in High Temperature Oxidation
}

\author{
Yves Wouters • Bruce Pint • Daniel Monceau
}

Published online: 14 December 2012

(C) Springer Science+Business Media New York 2012

The topic of water vapor effects is currently quite common in international meetings on the high temperature oxidation of metals and alloys. But one should keep in mind that this was not always the case. Twenty years ago, the high-temperature oxidation community was not entirely convinced of the water vapor's significance. But in the early 1990s, it became clear from both the field and laboratory-scale experiments that steam can often have a detrimental effect on scaling behavior. It is now well established that the presence of water vapor can strongly influence the growth kinetics as well as the morphology and/or the mechanical properties of thermallyformed oxide scales. With regard to oxidation kinetics, the formation of volatile hydroxides $\left(\right.$ e.g., $\left.\mathrm{Cr}(\mathrm{OH})_{3}\right)$ can play a highly influential role even down to relatively low reaction temperatures.

The papers presented in this topical issue cover a large number of materials (e.g., carbon, ferritic, austenitic and martensitic steels, ODS alloys, nickel-based super alloys, and $\mathrm{Zr}$ alloys) and industrials applications (e.g., nuclear and conventional fossil power plants, SOFC and high temperature electrolysis) focused on important applications such as energy production. Moreover, several papers in this issue are primarily concerned with advancing current fundamental understanding of the general mechanisms governing the water vapor effect.

\footnotetext{
Y. Wouters $(\bowtie)$

Science et Ingénierie des Matériaux et Procédés (SIMaP), University of Grenoble, 1130, rue de la Piscine, BP 75, 38402 Saint-Martin-d'Hères Cedex, France

e-mail: yves.wouters@simap.grenoble-inp.fr

B. Pint

Materials Science and Technology Division,

Oak Ridge National Laboratory, Oak Ridge, TN 37831-6156, USA

e-mail: pintba@ornl.gov

D. Monceau

INP Toulouse-CNRS, CIRIMAT, 31030 Toulouse, France

e-mail: daniel.monceau@ensiacet.fr
} 
The following key papers stem from presentations that were given at the 8th international conference on High Temperature Corrosion and Protection of Materials (HTCPM 2012), which was held at Les Embiez Island, France, on the 20-25th of May 2012. 